\title{
EXPERIMENTAL MEASUREMENTS AND NUMERICAL SIMULATION OF BRIDGE CONSTRUCTION WELDING AT LOW TEMPERATURES
}

This article describes experimental measurements and welding simulation by welding of bridge construction with thickness $30 \mathrm{~mm}$. The welded bridge plate was made from steel S355. Welding was carried out at low ambient temperature. Welding parameters and temperature cycles were measured during welding. Deformations of welded construction were obtained using optical system TRITOP before and after welding process. Experimental results except for deformations were used as boundary conditions for FEM simulation in SYSWELD. Temperature cycles, angular deformations and residual stresses were computed. The values of computed and measured angular deformations are almost identical. It follows that SYSWELD is able to predict angular and linear deformation with a good accuracy.

Keywords: Bridge construction, simulation of welding, SYSWELD.

\section{Introduction}

Welding is extensively used as a principal method of fabricating and assembling numerous metal products in shipbuilding, construction aviation, and automotive industries. One of the popular arc welding processes is manual metal arc welding (MMA) that has been applied in a wide range of plate thicknesses due to its ease and relatively high productivity. Welding is considered one of the most efficient, dependable, and economical means of fabrication to join metals permanently. However, distortion emerges as a result of the welding process which adversely affects the dimensional accuracy and esthetical value, which in turn can lead to expensive remedial work, which increases the overall fabrication costs [1]. Deformation in a welded part occurs due to non-uniform expansion and contraction of the weld metal and adjacent parent metals caused by complex temperature changes during the welding process. In addition, the deformation resulting from the welding process can also induce residual stress, which may significantly influence the structural performance of the welded structure [2].

Multipass butt is widely used in bridge construction. To minimize production cost, it is important to understand the distortion behaviour of multipass welding, which can be predicted by using simulation approach. The computational analysis can be used to achieve good welding quality and effective welding design in bridge construction [3 and 4].

\section{Simulation system SYSWELD}

SYSWELD integrates effects linked to metallurgical transformations in the thermal, mechanical and hydrogen diffusion analysis process. Simulation is broken down into a number of successive steps due to the modular aspect of the product. Figure 1 illustrates interaction between the various modules, with the two principle modules shown shaded. The electromagnetism module is used to compute current densities, and thus determine Joule effect power dissipation. Typical applications for this module include induction heating. It should also be noted that a powerful link has been developed between the thermo-metallurgical model and the electro-kinetic model, for simulation of processes such as spot-welding. The hydrogen diffusion computation module, with integration of trapping effects, is also of major interest for the study of cold cracking of steels following welding process [5].

Simulation is consequently conducted in a number of successive steps (with the results of one step forming input data for the following step):

thermal and metallurgical computation (determination of thermal cycles and metallurgical phase proportions according to space and time),

mechanical computation (stresses and residual strains), computation of hydrogen diffusion, integrating the effect of temperature, stresses and traps (reversible or irreversible) [6 and 7].

\footnotetext{
* Radoslav Konar, Marek Patek, Milos Mician

Department of Technological Engineering, Faculty of Mechanical Engineering, University of Zilina, Slovakia

E-mail: radoslav.konar@fstroj.uniza.sk
} 


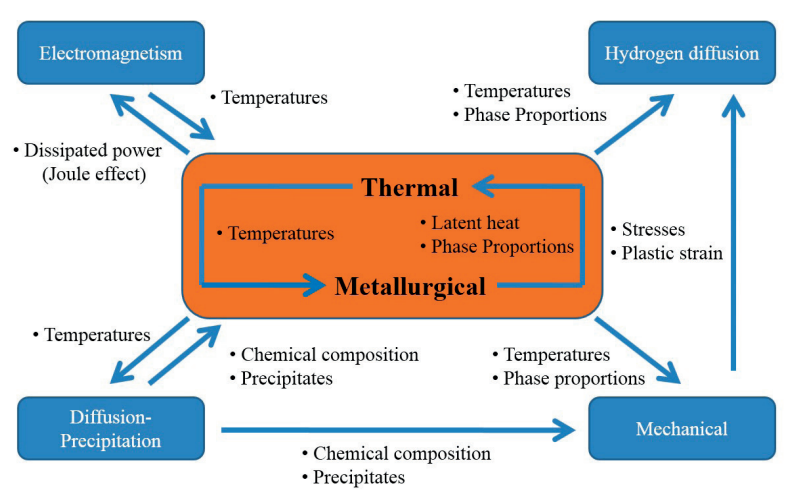

Fig. 1 General architecture of SYSWELD [8]

\section{Experimental part}

At the experimental part of article experimental measurement at the welding process and simulation of steel sheet with $30 \mathrm{~mm}$ thickness welding at the low temperature are described. Experiment was focused to observe deformational influence of welding and thermal expansion of material to the welded part.

\subsection{Experimental sample}

Experimental sample was made of steel S355J2G3 with chemical composition specified in Table 1.

The sample was composed of two parts with dimensions of $1320 \times 450 \times 30 \mathrm{~mm} \quad$ (Fig. 2). The sample was welded by asymmetrical double-V-groove weld according to WPS protocol.

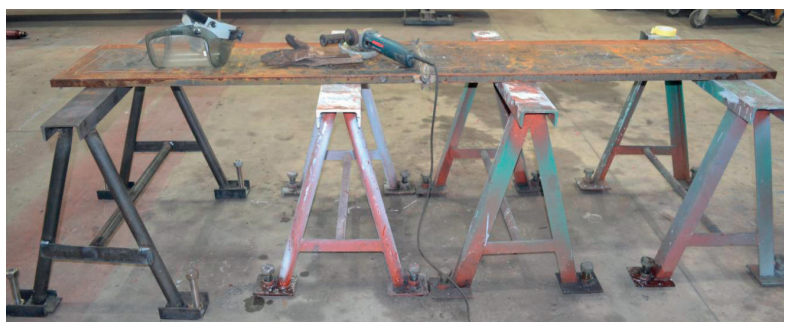

Fig. 2 Experimental sample

Scheme of weld edge preparation is shown in Fig. 3. Experimental sample was after tacking exposed to influence of negative ambient temperatures. Exterior ambient temperature at winter season was used to achieve negative temperature of the sample during welding process. Welded joint was made by MMA method (111 according to STN EN ISO 4063) at the ambient temperature about $-10{ }^{\circ} \mathrm{C}$. Made weld consists of 26 weld beads from which 11 were deposited in PE position and 15 in PA position (in terms of STN EN ISO 6947). The welding sequence of individual weld beads is shown in Fig. 3.
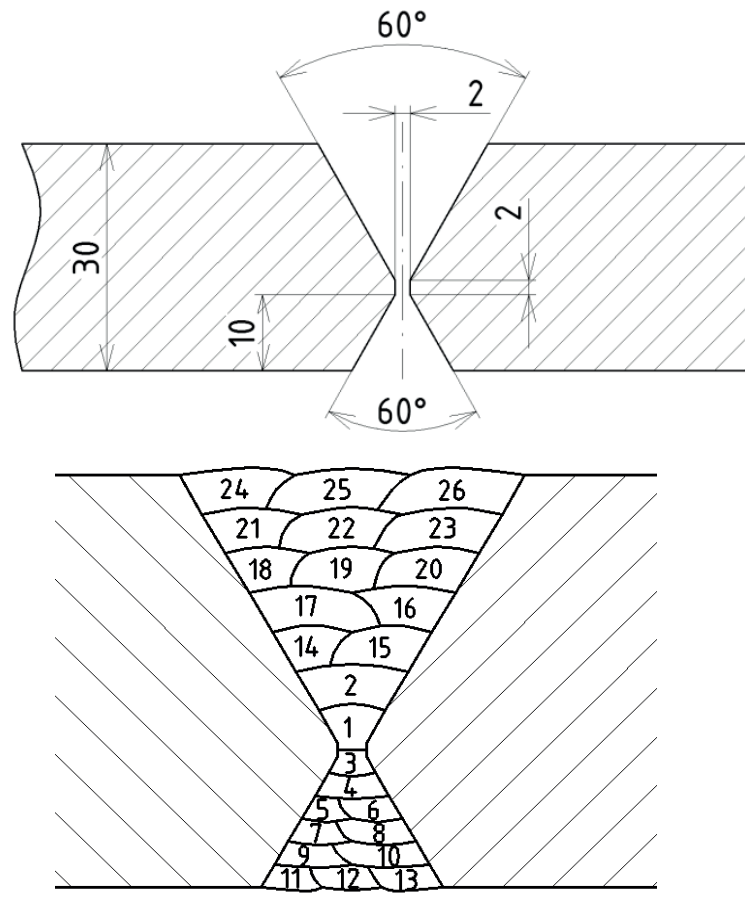

Fig. 3 Scheme of weld edge preparation (up) and welding sequence (down)

The sample was preheated by oxyacetylene flame to the temperature $180{ }^{\circ} \mathrm{C}$ before welding process and interpass temperature was maintained at temperature $300{ }^{\circ} \mathrm{C}$ during welding. Electrode CONARC 49 (E 463 B 32 H5 according to STN EN ISO 2560 standard) was used as filler material.

\subsection{Experimental measurements}

Experimental measurements can be divided into two parts:

- measuring of welding parameters and thermal cycles during and after welding,

- measuring of displacement in chosen points due to welding influence - thermal expansivity of material caused by change of ambient temperature [9].

\begin{tabular}{|c|c|c|c|c|c|c|c|c|c|c|c|c|}
\hline \multicolumn{10}{|c|}{ Chemical composition of steel S 355 (\%) } \\
\hline $\mathrm{C}$ & $\mathrm{Si}$ & $\mathrm{Mn}$ & $\mathrm{Cu}$ & $\mathrm{Al}$ & $\mathrm{Cr}$ & $\mathrm{Mo}$ & $\mathrm{Ni}$ & $\mathrm{V}$ & $\mathrm{Ti}$ & $\mathrm{Nb}$ & $\mathrm{P}$ & $\mathrm{S}$ \\
\hline 0.166 & 0.375 & 1.440 & 0.017 & 0.044 & 0.050 & 0.004 & 0.034 & 0.049 & 0.003 & 0.003 & 0.018 & 0.005 \\
\hline
\end{tabular}


Welding parameters and thermal cycles were measured by PC that allowed observed values on-line. Measuring system TRITOP was used to determine displacement of selected points [9].

\subsubsection{Measuring and examination of thermal cycles}

Thermal cycles were measured by 16 thermocouples. The points where the thermocouples were placed, allowed detailed time description of thermal fields near the weld during and after welding when the experimental sample was cooled (Fig. 4).

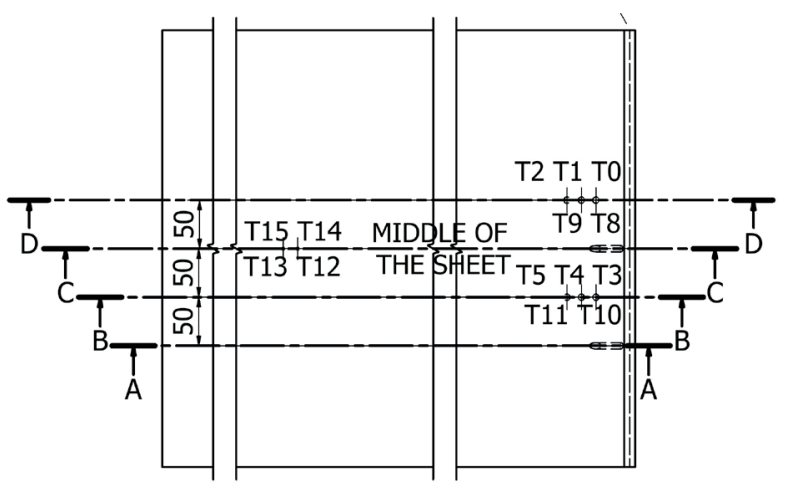

a) upper view

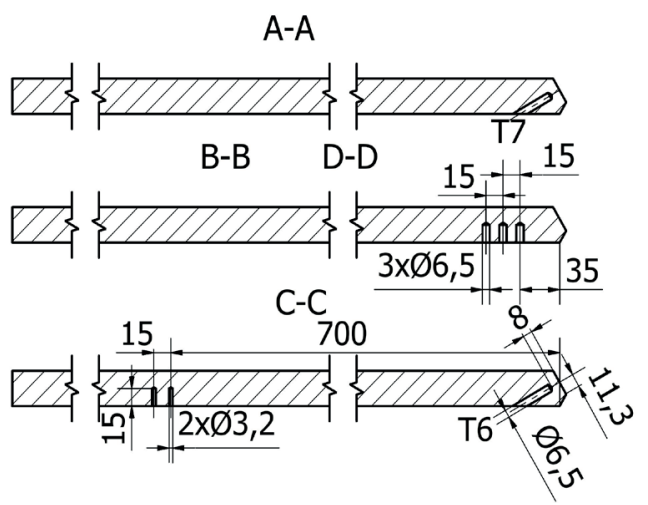

b) cross-section view

Fig. 4 Location of thermocouples on the welded plates

Thermal cycles recorded by thermocouples T0, T6, T10 (Fig. 5) were analysed to better comparing of thermal cycles obtained by experiment and simulation. Characteristic parameter $\mathrm{T}_{\text {max }}$ was determined for the first 4 beads. Maximal temperature $T_{\text {max }}$ of the cycle is the most appropriate characteristic parameter of thermal cycle to verify the accuracy of the simulation (Table 3 ).

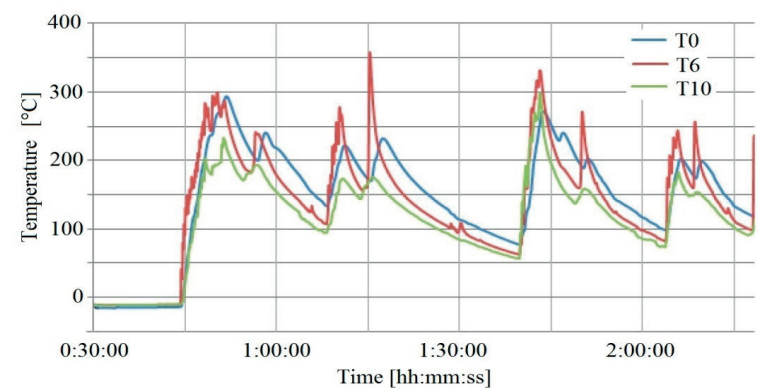

Fig. 5 Thermal cycles of thermocouples T0, T6 and T10 for the first 4 weld beads

Sample for macrostructural analysis was prepared from made weld. Macrostructural evaluation was in compliance with STN EN 1321 standard. Individual weld beads and their heat affected zones can be observed on macrostructural photography (Fig. 6). Macrostuctural photography has also served as a background for macrostructure digitalization, which is important initial parameter of simulation.

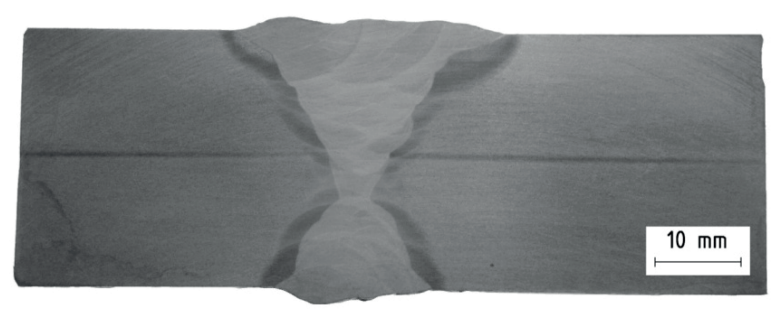

Fig. 6 Macrophotography of welded joint, etch. $5 \%$ Nital

\subsubsection{Measuring of displacement}

Deformations of welded plates were measured by optical system TRITOP. This system measured displacement in properly chosen points. Displacement of points was measured 4 times. The first measurement (M1) was performed after tacking the sample in the manufacturing hall. The ambient temperature was about $20{ }^{\circ} \mathrm{C}$. The sample was exposed to influence of negative ambient temperature after that measurement. When the sample temperature was steady in whole volume at about $-10{ }^{\circ} \mathrm{C}$, the second measurement (M2) was performed. Third measurement (M3) was performed after welding and stabilizing the temperature at about $-10{ }^{\circ} \mathrm{C}$. The last measurement (M4) was realized in the hall where ambient temperature was about $13{ }^{\circ} \mathrm{C}$. Based on measurements of individual point displacements angular deformation of welded plates was analysed. Location and identification of analysed planes formed by three points are shown in Fig. 7. 


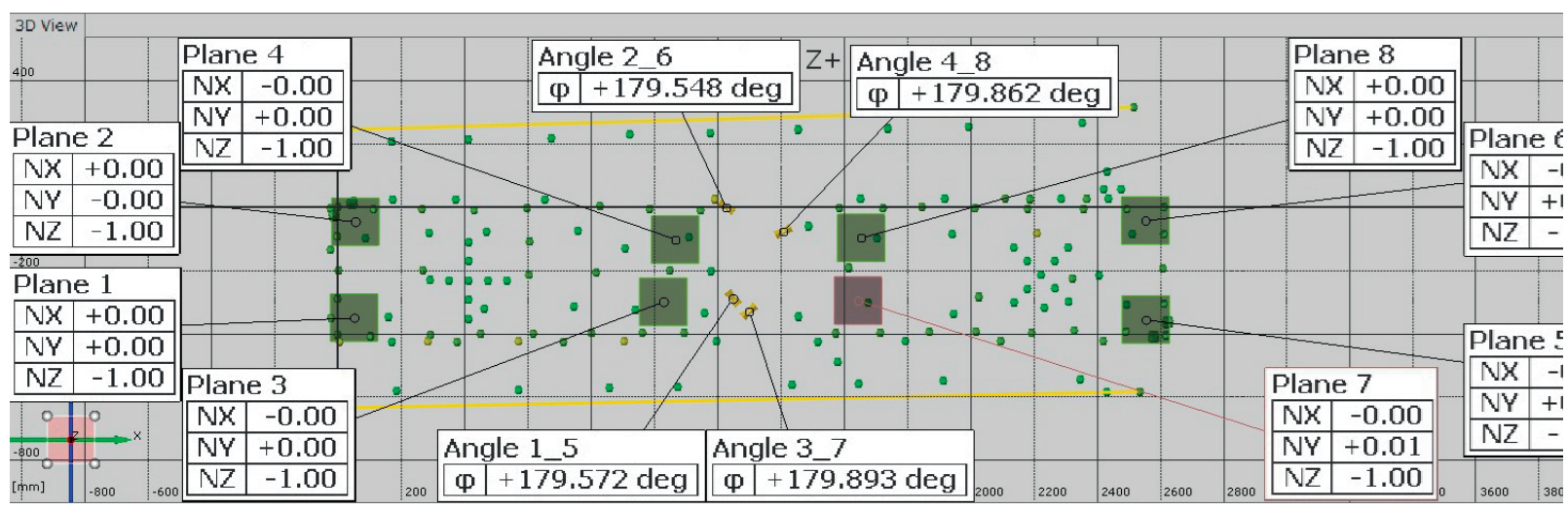

Fig. 7 Location of analysed planes and angles on welded plates

Angular deformation of sample were computed as the difference between the individual measurements (Table 2).

Angular changes between analysed planes

Table 2

\begin{tabular}{|c|c|c|c|}
\hline \multirow{2}{*}{$\begin{array}{c}\text { Angular } \\
\text { change }\end{array}$} & \multicolumn{3}{|c|}{ Compared measures } \\
\cline { 2 - 4 } & $\mathrm{M} 2$ - M1 & $\mathrm{M} 3$ - M2 & M4 - M3 \\
\hline$\Delta \Phi_{1,5}\left({ }^{\circ}\right)$ & -0.046 & -0.033 & 0.01 \\
\hline$\Delta \Phi_{2,6}\left({ }^{\circ}\right)$ & -0.095 & 0.027 & 0.01 \\
\hline$\Delta \Phi_{3,7}\left({ }^{\circ}\right)$ & 0.051 & 0.027 & -0.017 \\
\hline$\Delta \Phi_{4,8}\left({ }^{\circ}\right)$ & - & 0.217 & 0.174 \\
\hline
\end{tabular}

Maximal angular deformation of welded plates was detected between planes 4 and 8 with dimension $0.217^{\circ}$.

\section{Numerical simulation of welding at low temperatures}

Based on experimental findings the numerical simulation in programme SYSWELD was processed and obtained results were verified with measured results after welding.

\subsection{Definition of initial parameters of simulation}

Some simplifications were done at the numerical model because of wide dimensions of the real sample. Symmetrical 2D model was used for numerical simulation. Symmetrical axis of model is identical to the vertical axis of the weld. Digitized macrostructure was created in AutoCAD software and then was converted to FEM mesh (Fig. 8) in programme Visual MESH [10].

Material and physical properties were generated from SYSWELD database for material S355J2G3.
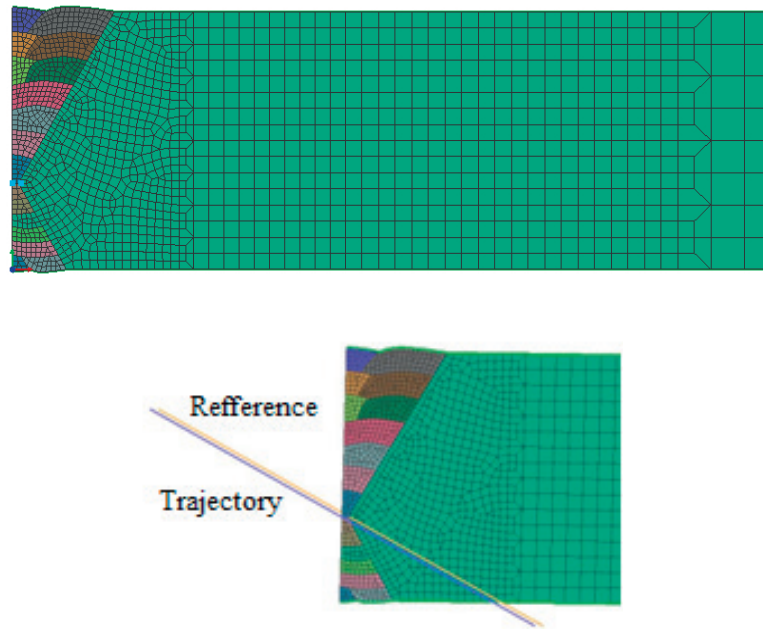

Fig 8 Finite element mesh of $2 \mathrm{D}$ model

2D Gaussian heat source was used for material preheating and Goldak's double-ellipsoidal heat source was used for simulation of welding. Parameters of heat source models were defined separately for preheating and for each weld beads. Welding process was simulated at ambient temperature $-10^{\circ} \mathrm{C}$. Heat exchange from material to atmosphere had to be modified. Heat flow coefficient for this purpose was $q=10 \mathrm{~W} \cdot \mathrm{m}^{-2}$.

\subsection{Thermal analysis results}

The thermal analysis was computed after definition of initial parameters for welding. Simulation thermal fields of beads corresponded with real thermal fields of beads, which can be observed on macrophotography. Thermal cycles were generated at the same points as thermocouples were placed on the sample (Fig. 9). Maximal temperature $\mathrm{T}_{\max }$ of three thermal cycles was determined for four weld beads from experimentally measured and simulated thermal cycles. Its values are in Table 3. 


\begin{tabular}{|c|c|c|c|c|c|c|c|c|c|c|c|c|}
\hline \multirow{4}{*}{$\mathrm{T}_{\max }\left({ }^{\circ} \mathrm{C}\right)$} & \multicolumn{12}{|c|}{ Weld bead } \\
\hline & \multicolumn{3}{|c|}{1} & \multicolumn{3}{|c|}{2} & \multicolumn{3}{|c|}{3} & \multicolumn{3}{|c|}{4} \\
\hline & \multicolumn{3}{|c|}{ Thermocouple } & \multicolumn{3}{|c|}{ Thermocouple } & \multicolumn{3}{|c|}{ Thermocouple } & \multicolumn{3}{|c|}{ Thermocouple } \\
\hline & T0 & T6 & $\mathrm{T} 10$ & T0 & T6 & $\mathrm{T} 10$ & T0 & T6 & $\mathrm{T} 10$ & T0 & T6 & $\mathrm{T} 10$ \\
\hline Simulation & 255.3 & 469.4 & 255.0 & 168.5 & 343.2 & 168.0 & 164.7 & 259.3 & 164.2 & 166.5 & 261.3 & 165.8 \\
\hline Experiment & 240.5 & 240.9 & 193.8 & 231.9 & 357.6 & 175.6 & 202.2 & 270.9 & 158.9 & 198.2 & 256.1 & 153.8 \\
\hline
\end{tabular}

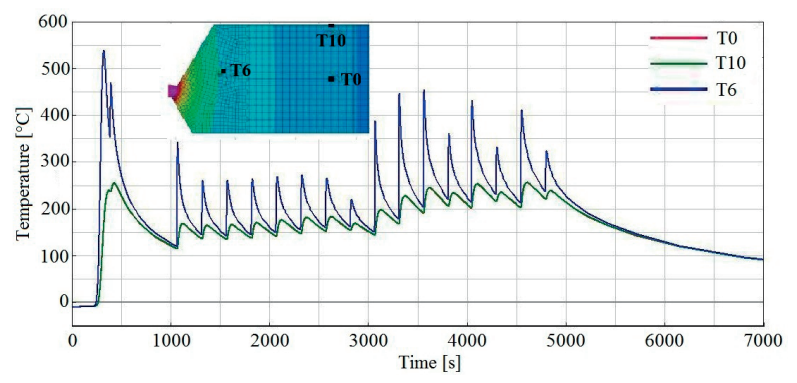

Fig. 9 Thermal cycles of simulated welding process

Values of parameter $\mathrm{T}_{\max }$ obtained by simulation and experiment reached a good agreement. The maximal deviation between experiment and simulation was $18.4 \%$.

\subsection{Mechanical analysis results}

Mechanical analysis of welding allows getting information about values and distribution of longitudinal, transversal, residual stresses by von Mises and deformation of weldments. Residual stresses by von Mises in weld construction computed in SYSWELD are shown in Fig. 10. The maximal value of residual stress in specific node was $1,018 \mathrm{MPa}$. This value is only approximate because it was calculated just for discrete node. Location of this maximal stress value was in the weld root.

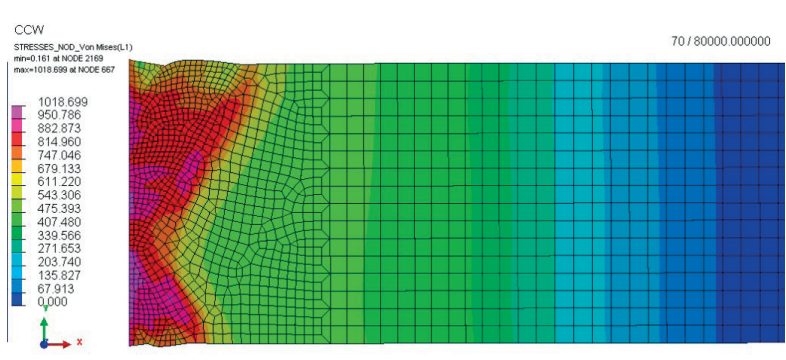

Fig. 10 Von Mises residual stresses of weld construction

To better compare measured and simulated welding deformations, angular deformation were computed. Computation of angular deformation was based on displacement in $\mathrm{Z}$ axis of chosen points and total length of metal sheet model $(1,321 \mathrm{~mm})$. Values of angular deformation after simulation of welding are listed in Table 4.

Angular deformation values obtained by simulation in 2D symmetrical model represent only half of real deformation value. Resulting value of angular deformation is $0.212^{\circ}$ which is in good agreement with experimentally obtained deformation $\left(0.217^{\circ}\right)$.

\section{Conclusion}

This article describes experimental measurements and numerical simulation during welding of bridge construction at low temperatures. Results of thermal cycles and weld macrostructure were used as boundary conditions for the simulation in SYSWELD. Residual stresses and angular deformation were calculated. Calculated angular deformations were almost identical to the experimentally measured deformations by optical system

\begin{tabular}{|c|c|c|c|c|c|c|c|c|c|}
\hline \multicolumn{9}{|c|}{ Angular deformation } \\
\hline Layer & 1 & 2 & 3 & 4 & 5 & 6 & 7 & 8 & \\
\hline Bead & 1 & 2 & 3 & 4 & 5 & 6 & 7 & 8 & 9 \\
\hline Deformation $\left({ }^{\circ}\right)$ & 0.074 & 0.851 & 0.559 & 0.299 & 0.084 & -0.095 & -0.254 & -0.382 & -0.473 \\
\hline Layer & 9 & 10 & \multicolumn{2}{|c|}{11} & \multicolumn{2}{|c|}{12} & \multicolumn{4}{|c|}{13} & - \\
\hline Bead & 10 & 11 & 12 & 13 & 14 & 15 & 16 & 17 & - \\
\hline Deformation $\left({ }^{\circ}\right)$ & -0.478 & -0.349 & -0.217 & -0.119 & -0.063 & 0.019 & 0.036 & 0.106 & - \\
\hline
\end{tabular}


TRITOP. The results of experiments and experiences can be concluded that the program SYSWELD is able to calculate deformations of welded construction within a tolerance of $10 \%$.

\section{Acknowledgement}

This work has been supported by Scientific Grant Agency of Ministry of Education of the Slovak Republic, grant VEGA: 1/0547/11, KEGA: 039ZU-4/2011, and non-profit organization EkoFond project No. 561/PG04/2011.

\section{References}

[1] FENG, Z.: Processes and Mechanisms of Welding Residual Stress and Distortion, CRC Press, USA, 2005, ISBN 978-0-8493-3467-2.

[2] TOTTEN, G., HOWES, M., INOUE, T.: Handbook of Residual Stress and Deformation of Steel, AMS International, Materials Park, 2002, ISBN 0-87170-729-2.

[3] KONAR, R., MICIAN, M.: Numerical Simulation of Residual Stresses and Distortions in Butt Weld in Simulation Programme SYSWELD, Communications - Scientific Letters of the University of Zilina, vol. 14, No. 3, 2012, 49-54, ISSN 1335-4205.

[4] MORAVEC, J.: Influence of Welding Parameters on Weld Pool's Geometry in Shielding Gas Welding, Pollypress : Liberec, 2011, ISBN 978-80-7372-805-2.

[5] MESKO, J. et al.: Shape of Heat Source in Simulation Program SYSWELD using Different Types of Gases and Welding Methods, Strojirenska technologie, 2011, No. 5, 6-11, ISSN 1211-4162.

[6] BREZNICAN, M., et al.: The Simulation of Influence of Quenching Temperature on Properties of Bearing Rings, Manufacturing Technology, vol. 13, No. 1, 2013, 20-25, ISSN 1213-2489.

[7] NOVAK, P., MESKO, J., ZMINDAK, M.: Finite Element Implementation of Multi-pass Fillet Weld with Phase Changes, Manufacturing Technology, 2011, vol. 13, No. 1, 79-85, ISSN 1213-2489.

[8] KONAR, R., MICIAN, M., HOPKO, A.: Analysis of Boundary Conditions for the Simulation of Welding at the Repair of Gas Pipelines with Steel Sleeve, Communications - Scientific Letters of the University of Zilina, vol. 13, No. 4, 2011, 36-39, ISSN 13354205.

[9] ZMINDAK, M., NOVAK, P., MESKO, J.: Numerical Simulation of Arc Welding Processes with Metallurgical Transformations, Metalurgija, vol. 49, No. 2, 2010, 595-599, ISSN 0543-5846.

[10] SLADEK, A., et al.: The Roundness and Microstructure of Thin-wall Bearing Rings, Manufacturing Technology, vol. 12, No. 13, 2012, 237-241, ISSN 1213-2489. 